\title{
Self-Efficacy and Its Association with Locus of Control in Diabetes in Turkey
}

\author{
Mustafa Kilic ${ }^{1}$, Selda Arslan² \\ ${ }^{1}$ Selcuk University, Faculty of Nursing Konya, Turkey. \\ ${ }^{2}$ Necmettin Erbakan University, Faculty of Nursing Konya, Turkey. \\ Correspondence Author: Mustafa Kilic \\ E-mail: mustafakilic@selcuk.edu.tr
}

Received: 06.03.2020 Accepted: 17.08.2021

\begin{abstract}
Objective: This descriptive-relational study was conducted to determine self-efficacy levels of individuals with type 2 diabetes, relationship between these levels both some sociodemographic characteristics and health locus of control.

Methods: The sample of this study was occurred 325 patients with diabetes who applied to the health care center constituted. Data were collected via 'Questionnaire Form', 'Self-efficacy in Diabetes Scale' and 'Multidimensional Health Locus of Control Scale'.

Results: The average age of participants was $53.3 \pm 8$ years, $51.4 \%$ of participants were women. It was found that the diagnosis time $8.7 \pm 7.2$ years, the level of $\mathrm{HbA1c}$ was $8.2 \pm 1.1$. In the sub dimensions of Diabetes Self-efficacy Scale, the patients got points as follows; sub dimension

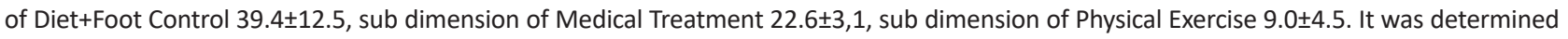
that in Multidimensional Health Locus of Control Scale, the patients got the highest points from the sub dimension of Powerful Others Locus of Control. A positive but weak level relation was determined between self-efficacy both total and subdimensions grades dimensions of health locus of control scale $(p<0.05)$. According to mulltiple regression analysis, variables in the model were the age range of $30-40$ years, not exercising, not obeying the diabetes regimen has been detected.
\end{abstract}

Conclusion: It is seen that patients with DM have medium level of self-efficacy and tend to believe the effects of external forces at a higher rate in the management of the disease.

Keywords: Health locus of control, nursing, self-efficacy, type 2 diabetes

\section{INTRODUCTION}

It is important for diabetic population to acquire positive health behaviors by arranging their life style, as diabetes mellitus (DM) is a chronic disorder affecting all aspects of life. Described as individuals' believing themselves, self-efficacy is a determinant so as to develop and maintain positive health behaviors and a significant factor defining how individuals feel, consider and behave (1-3). One of the concepts accounting for different behaviors individuals exhibit for DM, the locus of control is the perception explaining that positive or negative events affecting individual health status occur as a result of the behaviors or with the effect of external forces such as chance or accidents $(4,5)$. While those perceiving the consequences of events as an extension of their direct behaviors are described as "internally controlled individuals", others believing that the consequences are independent of their own behaviors, and that the control are due to other factors out of their own are described as "internally controlled". Internally controlled individuals consider that the control of the events encountered and consequences is in their hands, and tend to take the responsibility of their own health and to display positive health behaviors in order to maintain and develop a healthy life style. Externally controlled individuals, however, seek the consequences of the events they face in the forces out of their domain. Such individuals do not wish to take responsibilities due to the factors, such as the sensivity to psychological problems and the association between satisfaction, and social and environmental conditions, and consider their health status is dependent on fate and chance (5-8).

In the nursing management of chronic disorders such as DM, such indicators as health control focus are important to be evaluated to develop patients' self-efficacy. In studies investigating the effects of health control focuses on DM, the rates of regular diet and exercises, $\mathrm{HbA} 1 \mathrm{c}$ values, self-efficacy levels and self-care behaviors were observed to be affected positively, when internal control focus increased (9-12).

Given that health control focus is the determinant of patients' behaviors, and self-efficacy is also an important component of maintaining these behaviors, nurses' determination of health control focus and self-efficacy levels of patients plays a part in individualized health care. Because the number of studies assessing both of these variables is limited, the 
present study was designed and performed to determine the levels of health control focus and self-efficacy in patients with type 2 DM.

\subsection{Study Questions}

1. What are the self-efficacy levels of patients with type 2 DM?

2. Is there an assciation between health control focuses and self-efficacy levels of type 2 diabetic individuals'?

3. What are the determinants of the self-efficacy level of diabetes patients?

\section{METHODS}

\subsection{Study Type}

The present study was designed and performed as a descriptive-relational type of research.

\subsection{Study Setting and Features}

The study was performed in three health care centers in three counties in the city centre, for the samples include and represent all regions in the province of Konya/Turkey (Konya is a region in Central Anatolia in Turkey). The reasons why health care centers were chosen were associated with the following: the wish to evaluate patients with type $2 \mathrm{DM}$ in settings where they live, lack of factors to affect directly the health control focus and self-efficacy levels of type 2 DM patients and others such as access to health facilities and performing diabetic treatment regularly in medical settings.

\subsection{Sample Size}

The samples participating in the study were composed of diabetic population registered to the automation system of The Turkish Ministry of Health in 2015. While detecting the number of samples, the sample size was defined as 325 with the acceptance of $95 \%$ confident interval (CI), 0.05 as significance and 0.10 as the effect of anticipation (13). Inclusion criteria for the study were; (i) to have diagnosis of type $2 \mathrm{DM}$ at least fort he last six months, (ii) to be between the ages of 18-65, (iii) to be graduation at least from a primary school. Those with the history of a diagnosed psychiatric disorder and communication problems due to different native languages were excluded out of the study.

\subsection{Tools and Methods for Data Collection}

The questionnaire was prepared by the researchers in light of literature (14-16). Developed by Van Der Bijl et al. (17), the Self-Efficacy Scale (SES) consisting of four subdimensions and 20 items was also used. In Turkish version of SES, the validity and reliability of which were developed by Kara et al. (18), three subscales were put into the scale. The Cronbach's alpha value was found as 0.89 for the scale. In our study, the Cronbach's alpha value was found as 0.91 .
Developed by Wallston et al. (19) and with 18 items and three subscales, the Multidimensional Health Locus of Control Scale (MHCL), including the control focuses of internal health, powerful others and chance, was used as the second scale in the study $(19,20)$. The relaibility and validity of Turkish version were implemented by Ustundag and Budak. The in-consistency coefficient of MHCL was found as 0.63 . The Cronbach alpha was calculates as 0.61 in our study.

\subsection{Data Collection}

In collecting data, patients with DM were informed about the design of the study by practitioners in the centers, and all patients with DM were consecutively included into the study by starting from the first patient. On reaching the targeted number in the calculation of the sampling, data collection was discontinued. Due to including human participants, the study was reviewed by the local ethics committee and performed in accordance with the ethical standards laid down in the 1964 Declaration of Helsinki and its later amendments, Informed consent was also obtained from all participants prior to their inclusion into the study.

\subsection{Variables}

Dependent Variables : Total score of self-efficacy

Independent Variables : Sociodemographic Characteristics (Age, gender, marital status, educational status, profession, perception of economic status, individual cohabited, number of family members) and Health/Disease Characteristics (Body mass indeks-BMI, Use of alcohol and cigarette smoking, diagnostic time of DM, level of $\mathrm{HbA1c}$, History of DM in family, training for $\mathrm{DM}$, status of considdering sufficient training, status of regular health controls/follow-ups, type of diabetic treatment, status of regular drug use, status of regular exercise, compliance with regular diabetic dieting, subdimension scores of MHLCS)

\subsection{Data Analysis}

For statistical analysis of the data, a licensed SPSS 22 (IBM SPSS Inc, USA) package program was used. Data are summarized as number, percentage, mean, standard deviation. The suitability of normal distribution was determined by KolmogorovSmirnov test. Independent groups used t-test, pearson corelation and one-way analysis of variance. Tukey HSD test was used to search for variance. The relationship between self-efficacy and Health Control Center was assessed by pearson correlation analysis. Multiple regression analysisBackward model was used to determine the self-efficacy determinants. The following assumptions were taken into account while applying the multiple regression model: (i)linear relationship (ii)multivariate normality (iii)no multicollinearity (iv)homoscedasticity. Significance was evaluated as $p<0.05$.

\subsection{Ethics}

Approvals for this study were received from Selçuk University Health Sciences Faculty, Non-Interventional Clinical Researches Ethics Committee Decision no 2015/31 and 
Konya Public Health Directorate no 86104336/600. Written informed consent was obtained from each of the participate.

\section{RESULTS}

Of the patients with type $2 \mathrm{DM}$ in the study, mean age was found as $53.3 \pm 8.0$, and $51.4 \%$ were women, $88.9 \%$ were married, and $43.8 \%$ were housewives. While $63.4 \%$ of the study participants reported the perceived economic status as moderate, $58.9 \%$ declared that they lived with partners and children, and mean number of family members was found to be $3.76 \pm 1.8$. It was observed that mean body mass index (BMI) of the study participants was $30.1 \pm 4.8 \mathrm{~kg} / \mathrm{m} 2,76.9 \%$ were composed of non-users of tobacco, mean duration of cigarette smoking was $15.5 \pm 7.9$ years in users, $98.5 \%$ were non-users of alcoholic drinks, mean duration of using alcohol was as $12.6 \pm 4.8$ years among alcohol users, $52.6 \%$ had no exerciseon a regular basis, $66.5 \%$ did not comply with diabetic dieting, and $80.9 \%$ were regularly followed-up as to health controls. Among the study participants, it was also determined that mean duration of diagnosis of DM was $8.7 \pm 7.2$ years, while the level of $\mathrm{HbA} 1 \mathrm{c}$ was detected as $8.2 \pm 1.1,54.2 \%$ had no familial history of DM, $87.7 \%$ were trained as to DM, and $76.8 \%$ had diabetic training at sufficient level. Of the patients with DM, $69.2 \%$ were found to absorb only oral antidiabetic drugs, while $88 \%$ were detected to take in drugs regularly (Table 1 ).

Table 1. Baseline characteristics in the participants

\begin{tabular}{|c|c|c|}
\hline \multicolumn{3}{|c|}{ Mean \pm SD } \\
\hline Age & \multicolumn{2}{|l|}{$53.3 \pm 8.0$} \\
\hline \multirow[t]{2}{*}{ Body mass index } & \multicolumn{2}{|c|}{$30.1 \pm 4.8 \mathrm{~kg} / \mathrm{m}^{2}$} \\
\hline & Number & $\%$ \\
\hline \multicolumn{3}{|l|}{ Gender } \\
\hline Female & 167 & 51.4 \\
\hline Male & 158 & 48.6 \\
\hline \multicolumn{3}{|l|}{ Marital status } \\
\hline Married & 289 & 88.9 \\
\hline Single & 36 & 11.1 \\
\hline \multicolumn{3}{|c|}{ Perceived economic status } \\
\hline Bad & 41 & 12.6 \\
\hline Average & 206 & 63.4 \\
\hline Good & 78 & 24.0 \\
\hline \multicolumn{3}{|c|}{ Status of regular exercise } \\
\hline Yes & 79 & 24.3 \\
\hline No & 171 & 52.6 \\
\hline Sometimes & 75 & 23.1 \\
\hline \multicolumn{3}{|c|}{$\begin{array}{l}\text { Status of compliance with } \\
\text { regular diabetic dieting }\end{array}$} \\
\hline Yes & 216 & 66.5 \\
\hline No & 109 & 33.5 \\
\hline \multicolumn{3}{|c|}{ Status of regular health controls } \\
\hline Yes & 263 & 80.9 \\
\hline No & 62 & 19.1 \\
\hline \multicolumn{3}{|c|}{ Status of training for DM } \\
\hline Yes & 285 & 87.7 \\
\hline No & 40 & 12.3 \\
\hline Total & 325 & 100.0 \\
\hline
\end{tabular}

It's found that total score of self-efficacy scale is $71.1 \pm 16.8$, score of diet+foot control subdimension is $39.4 \pm 12.5$, score of medical treatment subdimension is $22.6 \pm 3.1$ and score of physical exercises subdimension is $9.0 \pm 4.5$. From the Multidimensional Health Locus of Control Scale, it's determined that score of internal health control focus is $25.3 \pm 6.8$, score of powerful others health control is $27.3 \pm 4.7$ and score of chance control focus is $17.9 \pm 5.5$. The scores of the scales are presented in Table 2.

Table 2. The distribution scores from the subscales of the selfefficacy and multidimensional health locus of control scales

\begin{tabular}{|c|c|c|c|c|}
\hline & Mean \pm SD & Median & Minimum & Maximum \\
\hline \multicolumn{5}{|l|}{ Self-efficacy Scale } \\
\hline Diet+Foot Control & $39.4 \pm 12.5$ & 43.0 & 12 & 60 \\
\hline Medical Treatment & $22.6 \pm 3.1$ & 25.0 & 5 & 25 \\
\hline Physical Exercises & $9.0 \pm 4.5$ & 10.0 & 3 & 15 \\
\hline Total & $71.1 \pm 16.8$ & 75.0 & 20 & 100 \\
\hline \multicolumn{5}{|c|}{ Multidimensional Health Locus of Control Scale } \\
\hline $\begin{array}{l}\text { Internal Health Control } \\
\text { Focus }\end{array}$ & $25.3 \pm 6.8$ & 27.0 & 6 & 36 \\
\hline $\begin{array}{l}\text { Powerful Others Health } \\
\text { Control Focus }\end{array}$ & $27.3 \pm 4.7$ & 27.0 & 6 & 36 \\
\hline Chance Control Focus & $17.9 \pm 5.5$ & 27.0 & 6 & 36 \\
\hline
\end{tabular}

When the association between subscale of diet+foot control of SES and health control focus scale was investigated, it was seen that internal health control and powerful others control focuses displayed a significant association, but there was no association between chance control focus and subscale of diet+foot control. It was observed that as the scores of internal health control and powerful others focuses increased, the score of diet+foot control increased and affected the internal health control focus weakly, while affecting the powerful others focus too weakly. However, as to the medical treatment subscale, a positive and too weak association was seen to be present only in powerful others focus. Also, in the physical exercise subscale, a positive and weak association was found with all the subscales of health control focus scale. Likewise, except for self-efficacy total score and the chance subscale of health control scale, an association at positive and weak level was observed with the other two subscales $(p<0.05)$. Association with the self-efficacy scale and health locus of control are presented in Table 3. In order to evaluate the effect of the independent variables, multiple regression analysis was used in all variables which affecting the total self-efficacy scale score were included in the analysis and it is presented in Table 4. According to analysis by Backward method, the most recent variables in the model were the age range of $30-40$ years $(p=0.008)$, not exercising $(p=0.009)$, not obeying the diabetes regimen $(p=0.000)$ has been detected. 
Table 3. Association with the self-efficacy scale and health locus of control

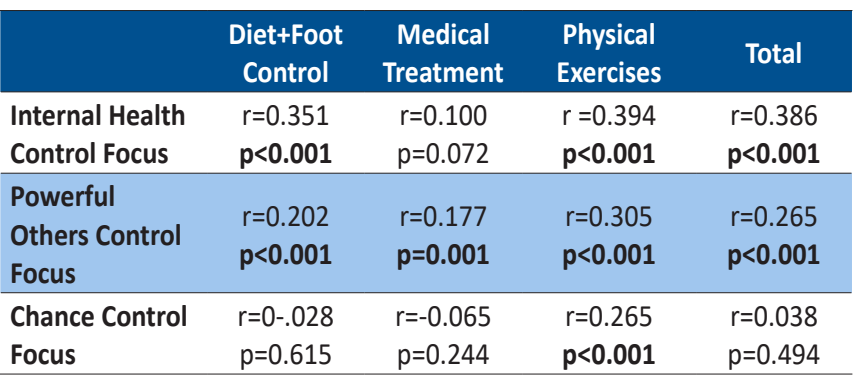

Table 4. Self-efficacy determinants of individuals with type 2 diabetes (Multiple regression analysis-Backward model)

\begin{tabular}{lccc} 
Determinant Factors & Beta & $\mathbf{t}$ & $\mathbf{p}$ \\
\hline Age $(30-40$ ages=1) & -0.125 & -2.705 & 0.008 \\
Exercise (No=1) & -0.129 & -2.630 & 0.009 \\
$\begin{array}{l}\text { Adherence to diabetic regimen } \\
\text { (No=1) }\end{array}$ & -0.739 & -15.144 & $<0.001$ \\
$\begin{array}{l}\text { Perceived efficency of training } \\
\text { (insufficient=1) }\end{array}$ & -0.121 & -2.625 & 0.010 \\
$\mathbf{F = 8 0 . 4 2 2} \mathbf{p}<\mathbf{0 . 0 0 1}$ & $\mathbf{R}=\mathbf{0 . 8 2 3}$ & $\mathbf{R}_{\text {square }}$ & $\mathbf{0 . 6 7 8}$ \\
\hline
\end{tabular}

\section{DISCUSSION}

Patients' total score of self-efficacy was determined as $71.1 \pm 16.8$. Previous studies were mostly evaluated in terms of self-efficacy total score, and the score was seen to range between 52-74 (21-23). Based on these findings, it may be suggested that diabetic population has moderate level of self-efficacy. It was seen that the lowest subscale score the participants received in our study was related to physical exercise, and the finding was cosistent with that found in the study by Al-Khawaldeh et al. in 2012 (22). We consider that individuals receive lower scores from physical exercise subscale, because physical exercises require behavioral changes and extra time, and due to obesity and other disorders associated with advanced age such as respiratory diseases or osteoarthritis. In terms of MHCL scores of the participants, it seems that individuals with DM tend to believe in the effects of external forces more in the disease management. In other studies, the internal control, the powerful others control and the chance control focuses were found as $27.2 \pm 6.3,30.8 \pm 5.2$ and $15.6 \pm 6.6$ in the study performed by Al Nawafa'h and

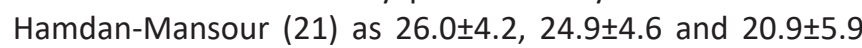
in the study by Aflakseir and ZarrinPour (24), as 25.9 \pm 5.6 , $23.7 \pm 5.6$ and $17.4 \pm 5.9$ in the study by Williams et al. (25), and $27.9 \pm 6.3,18.9 \pm 6.6$ and $25.3 \pm 5.6$ in the study conducted by Zahednezhad et al. (26), respectively. In various studies, it was observed that the internal control and powerful others control focuses were higher in the individuals with DM (9, 27). However, no studies related to the control perception of the patients with DM have been encountered in Turkey. The fact that the scores of internal control focus are close to those obtained from the powerful others control focus can be referred to higher rate of disease perception in patients. Individuals may also need others' assistance because the disease lead to complications and due to the chronic nature of the disease. This may also give rise to an increase in powerful others control focus. In addition, the fact that the priorities of the powerful others control and internal control focuses are variable in previous studies is considered to originate from educational and socio-cultural differences.

Given that the health control focus is the determinant of health behaviors $(16,26,28,29)$, the determination of health control focuses is of an importance in order to define self-efficacy in patients with type $2 \mathrm{DM}$. When the association between internal health focus and self-efficacy was investigated, as the score of internal control focus increased, the scores of diet+foot control, physical exercise and total self-efficacy were observed to be also increased. It is accepted that individuals with internal control focus believe their coping strategies against any negative events (29). The internal control focus was found to have a positive significance with mean score of self-efficacy (9). It may be suggested that the patients with higher rates of internal control focus comply with treatment modalities and believe their own strengths to cope with health challenges at a higher rate $(26,30)$. Despite the study reporting that those with higher rates of internal control focus care about their health status more (10), another study emphasizes that the internal control focus has no effects on the compliance with diet (24). It is also reported that the internal control focus is associated with age $(28)$, economical status $(28,31,32)$, physical and mental health status, and health behaviors (33). The fact that individuals with higher rates of internal control focus consider their problems encountered in daily life originate from their own features and strive to cope with these problems may increase such individuals' motivation, and the increase is one of the reasons demonstrating the association between self-efficacy and internal control focus.

In addition, we consider that the reason why the score of internal control focus in study participants was not so high is associated with lower rates of mean age and educational level. The fact that no significance was present in the medical treatment subscale may be explained by patients' adherence to drug regime and the inexistance of forceful behaviors in medical treatment. When the association between the powerful others control focus and self-efficacy was investigated, a significant difference was found to be present in all subscales. In the chance control focus, however, the difference was observed only in physical exercise subscale.

The patients in the study group are seen to increase the score of self-efficacy with the effects of external factors, such as family, friends or health professionals. In a study where the control perceptions of nurses and patients were compared, nurses and patients are seen to have higher rates of external control focus (21). In another study performed by Aflakseir and Zarrin Pour (2014) it was observed that while the individuals with external control focus had higher adherence to diet, those with chance control focus had lower adherence (24). In a study performed by Grotz et al. (2011) in German population, it was found that the elderly, those from lower socio-economic levels and emigrants had higher rates of 
powerful others control and chance control focuses (34). It was also reported in the same study that chance health focus was less related to health behaviors, such as physical activity, dental health or regular hospital visits.

Because individuals with external control and chance control focuses consider that all their failures are out of their own control, the rate of such individuals' motivation may be suggested to be lower. In addition, the socio-cultural environment including individuals with higher religious attitudes or faith also affects almost all types of control focuses (6). It should be kept in mind that patients with more fatalistic attitudes and approaches to health challenges are treated as a risk factor in terms of health behaviors, and chance may have some indirect effects on health behaviors.

Multiple regression analysis suggests that being ages between 30 and 40 years $(\beta 0.125)$, not doing exercise $(\beta=-0.129)$, not obeying the diabetes regimen $(\beta=-0.739)$ and perceived insufficient diabetes training $(\beta=-0.121)$ are determinants of the self-efficacy score. Other variables that were found to be significant in analyses were not identified as determinants. There are studies reporting that self-efficacy is related to age $(35,36)$, exercise $(23,37,38)$, compliance with the diabetes diet $(37)$ and training $(3,39,40)$ in the literature.

\section{CONCLUSIONS}

It is seen that patients with DM have medium level of selfefficacy and tend to believe the effects of external forces at a higher rate in the management of the disease. Based on these findings, control focuses of diabetic population should be defined meticulously, and the internal control focus should be improved to obtain their independency. Due to the limited sample size of our study, it is recommended to conduct studies with a larger sample size.

Acknowlegment: Authors declare that our full results have not been published previosly, are not under submission elsewhere. Abstract is presented as a oral presentation at $5^{\text {th }}$ International \& $16^{\text {th }}$ National Nursing Congress in Ankara/ TURKEY.

\section{REFERENCES}

[1] Bandura A. Self-efficacy. In: V.S.Ramachaudran, editor. Encyclopedia of human behaviour. 4. New York: Acemedic Press; 1994. p. 71-81.

[2] Ajzen I. Perceived behavioral control, self-efficacy, locus of control, and the theory of planned behavior1. Journal of Applied Social Psychology 2002;32(4):665-683.

[3] Wu S, Huang Y, Lee M, Wang T, Thung H, Wu M. Self-efficacy, self-care behaviour, anxiety, and depression in Taiwanese with type 2 diabetes: A cross-sectional survey. Nursing and Health Sciences 2013;15:213-219.

[4] Nugent LE, Carson M, Zammitt NN, Smith GD, Wallston KA. Health value \& perceived control over health: behavioural constructs to support Type 2 diabetes self-management in clinical practice. J Clin Nurs. 2015;24(15-16):2201-2210.
[5] Rotter J. Generalized expectancies for internal versus external control of reinforcement. Psychological Monographs: General and Applied 1966;80:1-28.

[6] Gürses í. Din eğitimi kişilik ilişkisi üzerine bir araştırma. TC Uludağ Üniversitesi Illâhiyat Fakültesi Dergisi. 2007;16(2):79122. (Turkish)

[7] Öztürk A, Metinoğlu İ. Kastamonu üniversitesinde öğrenim gören öğrencilerin sağlık denetim odağı algılama düzeyleri ve sağlık davranışlarına etkileri. Uluslararası Hakemli Akademik Spor Sağlık ve Tıp Bilimleri Dergisi 2012;2(4):65-79. (Turkish)

[8] Tabak R, Akköse K. Ergenlerin sağıık denetim odağı algılama düzeyleri ve sağlık davranışlarına etkileri. TAF Preventive Medicine Bulletin 2006;5(2):118-130. (Turkish)

[9] Chen S, Lin H. Relationships among health locus of control, psychosocial status and glycemic control in type 2 diabetes adults. Journal of Nursing and Care 2014:1-6.

[10] Cobb-Clark D, Kassenboehmer S, Schurer S. Healthy habits: the connection between diet, exercise, and locus of control. Journal of Economic Behaviour and Organization 2014;98:128.

[11] Morowatisharifabad M, Mahmoodabad S, Baghianimoghadam $\mathrm{M}$, Tonekaboni N. Relationships between locus of control and adherence to diabetes regimen in a sample of iranians. Int J Diabetes Dev Ctries 2010;30:27-32.

[12] O'Hea EL, Grothe KB, Bodenlos JS, Boudreaux ED, White MA, Brantley PJ. Predicting medical regimen adherence: the interactions of health locus of control beliefs. Journal of Health Psychology 2005;10:705-717.

[13] Cohen J, Cohen P, West SG, Aiken LS. Applied multiple regression/correlation analysis for the behavioral sciences. Third edition ed. Mahwah, NJ.: Lawrence Earlbaum Associates; 2003.

[14] Adam J, Folds L. Depression, self-efficacy, and adherence in patients with type 2 diabetes mellitus. The Journal for Nurse Practitioners 2014;10:646-652.

[15] Bohanny W, Wu S, Liu C, Yeh S, Tsay S, Wang T. Health literacy, self-efficacy, and self-care behaviours in patients with type 2 diabetes mellitus. Journal of the american Association of Nurse Practitioners 2013;25:495-502.

[16] O'hea E, Moon S, Grothe K, Boudreaux E, Bodenlos J, Wallston $\mathrm{K}$, et al. The interaction of locus of control, self-efficacy, and outcome expectancy in relation to $\mathrm{HbA1c}$ in medically underserved individuals with type 2 diabetes. J Behav Med. 2009;32:106-117.

[17] Van der Bijl JJ, Poelgeest-Eeltink AV, Shortridge-Baggett LM. The psychometric properties of diabetes management selfefficacy scale for patients with type 2 diabetes mellitus. J Adv Nurs. 1999;30:352-359.

[18] Kara M, Van der Bijl JJ, Shortridge-Baggett LM, Asti T, Ergunay $S$. Cross-cultural adaptation of the diabetes management selfefficacy scale for patients with type 2 diabetes mellitus: scale development. Int J Nur Stud. 2006;43:611-621.

[19] Wallston K, Wallston B, DeVellis R. Development of the multidimensional health locus of control (MHLC) scales. Health Education Monographs 1978;6:160-170.

[20] Wallston K, Stein M, Smith K. Form C of the MHLC scales: a condition-spesific measure of locus of control. Journal of Personality Assesment 1994;3,:534-553.

[21] Al Nawafa'h A, Hamdan-Mansour A. Correlates of health locus of control among patients diagnosed with type-II diabetes mellitus. Journal of Diabetes Mellitus 2015:190-197. 
[22] Al-Khawaldeh O, Al-Hassan M, Froelicher E. Self-efficacy, self-management, and glycemic control in adults with type 2 diabetes mellitus. Journal of Diabetes and its Complications 2012;26:10-61.

[23] Sarkar U, Fisher L, Schillinger D. Is self-efficacy associated with diabetes self-management across race/ethnicity and health literacy? Diabetes Care 2006;29:823-829.

[24] Aflakseir A, ZarrinPour R. Predicting adherence to diet regimen based on health locus of control: a cross sectional study. Iranian Journal of Diabetes and Obesity 2014;5:71-76.

[25] Williams J, Lynch C, Voronca D, Egede L. Health locus of control and cardiovascular risk factors in veterans with type 2 diabetes. Endocrine 2016;51:83-90.

[26] Zahednezhad H, Poursharifi H, Babapour J. Memory, health locus of control and adherence in type ii diabetic patients in Iran - Tabriz. Procedia - Social and Behavioral Sciences 2011;30:2621-2624.

[27] Fuscaldi F, Balsanelli A, Grossi S. locus of control in health and self-esteem in type-2 diabetic patients. Rev Esc Enferm USP. 2011;45:853-859.

[28] Lindström M, Rosvall M. Marital status, social capital and health locus of control: a population-based study. Public Health 2012;126:790-795.

[29] Trento M, Tomelini M, Basile M, Borgo E, Passera P, Miselli $\mathrm{V}$. The locus of control in patients with type 1 and type 2 diabetes managed by individual and group care. Diabet Med. 2008;25:86-90.

[30] Przybylski M. Health locus of control theory in diabetes: a worthwhile approach in managing diabetic foot ulcers? Journal of Wound Care 2010;19(6):228-233.

[31] Abredari H, Bolourchifard F, Rassouli M, Nasiri N, Taher M, Abedi A. Health locus of control and self-care behaviours in diabetic foot patients. Medical Journal of the Islamic Republic of Iran 2015;29:1-5.

[32] Poortinga W, Dunstan F, Lone D. Health locus of control beliefs and socio-economic differences in self-rated health. Preventive Medicine 2008;46:374-380.

[33] Keedy N. Health locus of control, self-efficacy, and multidisciplinary intervention for chronic back pain. Ph D Thesis, lowa University 2009.

[34] Grotz M, Hapke U, Lampert T, Baumeister H. Health locus of control and health behaviour: results from a nationally representative survey. Psychology, Health and Medicine 2011;16:129-140.

[35] DePalma M, Trahan L, Eliza J, Wagner A. The relationship between diabetes self-efficacy and diabetes self-care in american indians and alaska natives. American Indian and Alaska Native Mental Health Research 2015;22:1-23.

[36] Erol O, Enc N. Hypoglycemia Fear and Self-efficacy of Turkish Patients Receiving Insulin Therapy. Asian Nurs Res (Korean Soc Nurs Sci). 2011;5(4):222-228.

[37] Mishali M, Omer H, Heymann A. The importance of measuring self-efficacy in patients with diabetes. Family Practice 2011;28:82-87.

[38] Lee E, van der Bijl J, Shortridge-Baggett L, Han S, Moon S. Psychometric properties of the diabetes management self-efficacy scale in korean patients with type 2 diabetes. International Journal of Endocrinology 2014;1-9.

[39] Olgun N, Akdoğan-Altun Z. Sağlık inanç modeli doğrultusunda verilen eğitimin diyabet hastalarının bakım uygulamalarına etkisi. Hacettepe Üniversitesi Sağlık Bilimleri Fakültesi Hemşirelik Dergisi 2012;46-57. (Turkish)

[40] Gedik S, Kocoglu D. Self-efficacy level among patients with type 2 diabetes living in rural areas. Rural and Remote Health 2018;18: 4262. 